\title{
Proneural clusters of achaete-scute expression and the generation of sensory organs in the Drosophila imaginal wing disc
}

\author{
Pilar Cubas, José-Félix de Celis, Sonsoles Campuzano, and Juan Modolell \\ Centro de Biología Molecular, Consejo Superior de Investigaciones Científicas and Universidad Autónoma de Madrid, 28049 \\ Madrid, Spain
}

The proneural genes achaete (ac) and scute (sc) confer to Drosophila epidermal cells the ability to become sensory mother cells (SMCs). In imaginal discs, ac-sc are expressed in groups of cells, the proneural clusters, which are thought to delimit the areas where SMCs arise. We have visualized with the resolution of single cells the initial stages of sensory organ development by following the evolving pattern of proneural clusters and the emergence of SMCs. At reproducible positions within clusters, a small number of cells accumulate increased amounts of $a c-s c$ protein. Subsequently, one of these cells, the SMC, accumulates the highest amount. Later, at least some SMCs become surrounded by cells with reduced ac-sc expression, a phenomenon probably related to lateral inhibition. Genetic mosaic analyses of cells with different doses of $a c-s c$ genes, the $s c$ expression in $s c$ mutants, and the above findings show that the levels of ac-sc products are most important for SMC singling-out and SMC state maintenance. These products do not intervene in the differentiation of SMC descendants. The extramacrochaetae gene, an antagonist of proneural genes, negatively regulates sc expression, probably by interfering with activators of this gene.

[Key Words: Sensory organ precursors; achaete; scute; pattern formation; proneural cluster]

Received January 15, 1991; revised version accepted March 5, 1991.

Morphogenesis in multicellular organisms results from organized cell proliferation coupled with the differentiation of various cell types according to spatial arrangements. The adult cuticle of Drosophila contains thousands of sensory organs (SOs, chaetae, and sensilla of other kinds) whose type and position form a stereotyped pattern. Each $\mathrm{SO}$ is formed by the progeny of a single precursor cell, the sensory mother cell (SMC), which, during the third-instar larva or early pupa stages, is singled out from the population of imaginal disc cells or abdominal histoblasts (García-Bellido and Merriam 1971). A current model (Ghysen and Dambly-Chaudière 1989; Jan and Jan 1990) proposes that the generation of the pattern of SOs is a multistep process that begins when clusters of ectodermal cells, defined by pre-existing cues, acquire a proneural state. Later, by means of cell-cell interactions, an SMC is singled out from the cells of the proneural cluster and prevents its neighbors from following the same fate (lateral inhibition; Wigglesworth 1940). SMCs then undergo two differential divisions to yield four cells that will differentiate into the SO (Lawrence 1966; Bate 1978; Hartenstein and Posakony 1989).

Genetic analysis has identified a number of genes that act on one or several of these steps (Lindsley and Grell
1968; Jan and Jan 1990). Among them, the achaete (ac) and scute $(s c)$ genes, two members of the ac-sc complex (AS-C; García-Bellido 1979; Campuzano et al. 1985), are expressed in clusters of cells which, according to the fate map of the imaginal wing disc (Bryant 1975), roughly correspond to areas where SMCs should arise (Romani et al. 1989). Moreover, since hypomorphic ac or sc mutations cause the loss of SOs from allele-specific positions (García-Bellido 1979), while generalized expression of $a c$ and/or sc /Campuzano et al. 1986; García-Alonso and García-Bellido 1986; Balcells et al. 1988; Rodríguez et al. $1990)$ induces the formation of extra SOs in ectopic positions, it has been proposed that ac-sc confer to cells the capacity to become neural precursors. Their expression in groups of cells would define the proneural clusters, from which one or a few cells would be recruited to become SMCs (for review, see Ghysen and DamblyChaudière 1989; Jan and Jan 1990|.

The $a c$ and $s c$ proteins contain the basic helix-loophelix domain (bHLH) characteristic of a family of transcriptional regulators (Villares and Cabrera 1987; Murre et al. 1989a). This domain allows these proteins to dimerize with themselves and/or with other members of the family and to bind to specific DNA sequences (Murre et al. 1989b). This suggests that $a c$ and $s c$ are transcrip- 
tional regulators that control the activity of genes involved in SO differentiation, probably in combination with other HLH proteins, like that encoded by the gene daughterless (da) (Caudy et al. 1988; Dambly-Chaudière et al. 1988). The ability of HLH proteins to form heterodimers may also account for the antagonistic effect of extramacrochaetae $(\mathrm{emc})$ and hairy $(h)$ proteins on the proneural activity of $a c$ and $s c$ (Botas et al. 1982; Moscoso del Prado and García-Bellido 1984; García-Alonso and García-Bellido 1988). Both emc and $h$ contain the HLH motif but lack $(\mathrm{emc})$ or have an altered basic region (Rushlow et al. 1989; Ellis et al. 1990; Garrell and Modolell 1990). So, they may sequester $a c$ and $s c$ proteins in complexes inefficient for DNA interaction.

To analyze, at single-cell resolution, the relationship between the generation of the clusters of $a c$ and $s c$ expression and the emergence of SMCs, we have performed in situ hybridizations to whole discs using digoxigenin (DlG)-labeled probes (Tautz and Pfeifle 1989) in the A101.1F3 transformant line of flies, which allows early detection of SMCs by expressing the bacterial lacZ gene in these cells (Huang et al. 1991). With the help of anti-ac and anti-sc antibodies (Skeath and Carroll 1991), we have also analyzed the fine structure of the $a c$ and $s c$ expression clusters and their modifications in mutants. In addition, we have examined by genetic mosaic analysis the temporal requirement of $a c-s c$ functions for the development of each notum macrochaeta. We have found an intimate relationship between the spatial and temporal evolution of the $a c-s c$ clusters and the emergence of SMCs. Thus, SMCs appear at specific positions within clusters that are defined by increased levels of $a c-s c$ products. $a c-s c$ intervene in the process of SMC singling-out and SMC state maintenance, but not in the differentiation of the SMC descendants. Analysis of the patterns of $a c-s c$ expression in mutants underline the relevance of the levels of $a c-s c$ products for these developmental processes. Some of the results presented have also been independently obtained by Skeath and Carroll (this issue), there being essential agreement between their conclusions and ours.

\section{Results}

ac and sc expression precedes the appearance of SMCs

We have examined, in wing imaginal discs, the spatial and temporal relationship between the patterns of $a c-s c$ expression and the appearance of SMCs. Discs from A101.1F3 larvae were stained with X-gal, to reveal SMCs, and hybridized with ac or sc DIG-labeled probes, to show the distribution of $a c$ or $s c$ mRNA. Both mRNAs have similar distributions (not shown, and Romani et al. 1989), due to a reciprocal gene activation between $a c$ and sc (Martínez and Modolell 1991; Skeath and Carroll, this issue). Figure 1 shows examples of increasingly older discs hybridized with the $s c$ probe. The main finding is that SMCs appear in a sequence (for a more detailed description, see Huang et al. 1991), which is temporally preceded and spatially prefigured by the expression of $a c$ and $s c$. Thus, at $\sim 35 \mathrm{hr}$ before puparium formation (BPF), $s c$ is expressed in clusters of cells, but no or very few SMCs are detectable (Fig. 1A). Approximately $10 \mathrm{hr}$ later (Fig. 1B), several SMCs, like those for the PDC and APA macrochaetae, have become visible within clusters of $s c$-expressing cells. In the middle of the presumptive notum, a cell, which originates in a small and weakly expressing cluster, shows an increased $s c$ expression (Fig. $1 \mathrm{~B}$, arrowhead). It corresponds to the PSA macrochaeta precursor, which later will express lacZ (Fig. 1C). In the following hours, some clusters become more prominent and SMCs emerge in them, such as those for the ANP and PNP macrochaetae (Fig. 1C,D). Also, new clusters appear, like those at the presumptive wing margin (Fig. 1C) and PPA and ASA regions (Fig. 1D). The corresponding precursors will later become visible, either at $\sim 10 \mathrm{hr}$ BPF (wing margin, Fig. 1D) or several hours after puparium formation (APF) (PPA and ASA; not shown, and Huang et al. 1991). The ADC and ASC macrochaetae precursors appear several hours BPF within the clusters that previously gave rise to their posterior counterparts (Fig. 1E). Around puparium formation, $s c$ (and $a c$ ) expression disappear from many clusters (Fig. 1F). Those remaining will give rise to additional SMCs. Moreover, additional sites of $a c-s c$ expression appear AFP (not shown). It should be stressed that expression of $a c$ and $s c$ is a prerequisite for SMC development: $\operatorname{In}(1) s c^{10.1}$; A101.1F3 wing discs, which lack functional $a c-s c$ genes (García-Bellido 1979; Campuzano et al. 1985; Villares and Cabrera 1987), are devoid of lacZ-expressing cells (not shown).

The shape, size, and position of the proneural clusters are very reproducible when comparing discs of approximately the same age. Moreover, since SMCs become detectable, they are located in characteristic positions within clusters that in some cases (APA, trl, PDC) are clearly eccentric. This led us to examine, with higher resolution, the configuration of clusters using antibodies specific for the $a c$ and $s c$ proteins.

\section{SMCs preferentially accumulate ac-sc proteins}

The patterns of $a c$ and $s c$ protein accumulation are very similar (Skeath and Carroll, this issue; P. Cubas el al., unpubl.) and strongly resemble those of the corresponding mRNAs (cf. Fig. $1 \mathrm{~B}$ and $\mathrm{E}$ with Fig. $2 \mathrm{~A}$ and $\mathrm{B}$ ). The proteins are unambigously detected in discs as early as $40 \mathrm{hr}$ BPF and are restricted to cell clusters (not shown). As expected from their putative role as transcriptional regulators, the $a c-s c$ proteins are localized in nuclei. Within many proneural clusters, and depending on the developmental age, there is an intensely stained nucleus (Fig. 2A-C). It belongs to the SMC, as its position exactly matches that of the lacZ-expressing cells in the A101.1F3 discs. The enhanced abundance of $a c-s c$ proteins in SMCs is due, at least in part, to a system of specific activation of $a c-s c$ transcription in these cells (Martínez and Modolell 1991). This transcription is independently regulated from the expression in other cells of the cluster since, depending on the SMC, the presence 
of the proteins (and mRNAs) lasts longer or shorter than that in the respective cluster (see legend to Fig. 2). Staining of discs with anti- $\beta$-galactosidase and anti-sc antibodies (not shown) indicates that this increased expression starts earlier than the $\beta$-galactosidase accumulation; therefore, it may be the earliest known sign of SMC commitment. The increased abundance of $a c-s c$ proteins in SMCs may be related to SMC state maintenance. This double staining also reveals that $a c-s c$ proteins disappear from SMCs shortly before they undergo the first differential division (not shown).

\section{Anatomy of proneural clusters}

Clusters that give rise to only one SMC, that is, ANP,
PNP, ASA, PSA, and PPA, have a simple structure. They have a roughly circular outline and the nuclei at the center accumulate higher amounts of $a c-s c$ proteins than those at the periphery. The clusters grow in number of cells and in the intensity of staining until the time the SMC becomes discernible. When fully developed, these clusters contain 20-30 stained nuclei, except the PSA cluster, which shows only $\sim 10$ weakly stained nuclei. As shown below, SMC cells become slightly larger than neighboring cells.

Clusters that give rise to more than one SMC have a more complex evolution. We shall describe two examples.

The APA cluster The APA precursor becomes recognizable at approximately $30-25 \mathrm{hr}$ BPF in an eccentric

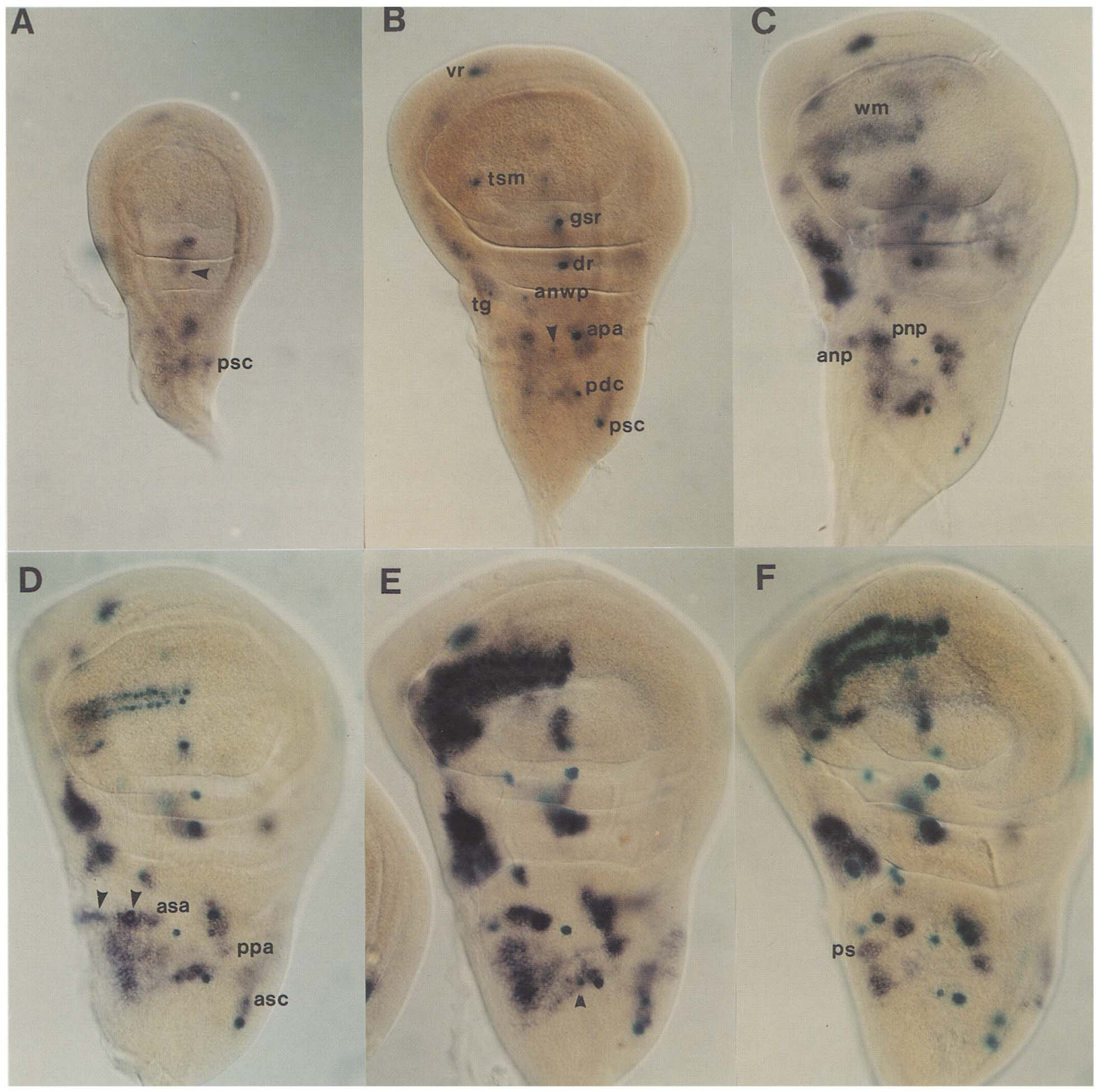

Figure 1. (See facing page for legend.) 
position within the cluster (Fig. 2D). Five to $10 \mathrm{hr}$ later, the cluster has enlarged, and the APA precursor is located at its anterior (left) edge (Fig. 2E). At the bottom edge, several nuclei are stained more intensely; one of them will probably become the trl precursor (Fig. 2C). Later, at approximately the time this precursor becomes visible, $a c-s c$ expression ceases in the APA precursor. Its position is revealed by an indentation in the cluster (Fig. $2 F)$. At the time of puparium formation, additional cells at the top of the cluster express ac-sc (Fig. 2G) and one of them will become the tr2 precursor.

The DC cluster In its early stages, this cluster is roughly elliptical (Figs. 1A and 2A). The PDC precursor is not yet detectable, and several centrally located nuclei are more intensely stained than others lopen arrow, Fig. 2D|. When the PDC precursor is distinguishable, the cluster is larger and the precursor is reproducibly located at the bottom right side of the cluster (Fig. $2 \mathrm{H}$ ). Intensely stained cells are then found more anteriorly (toward the left) at the place where the ADC precursor later appears, also off this center (Fig. 2I). Note that when both the ADC and PDC nuclei are visible, they are located at different planes (Fig. 2J and $\mathrm{K}$ ).

Some time after the PDC, PSA, APA, and PNP SMCs and several relatively isolated sensilla campaniformia precursors at the dorsal wing radius become recognizable by their intensely stained nuclei, they appear surrounded by cells not expressing or expressing lower amounts of $a c-s c$ than the rest of the cluster (Fig. 2B, C, H, and J). These halo-like zones, one to two cell diameters in width, are also seen in discs stained for $\beta$-galactosidase and $s c$ mRNA [Fig. 1C (PDC precursor) and Fig. ID (PNP precursor|]. In the case of the APA precursor, some time after this cell has divided and stopped expressing $a c-s c$, the area of nonexpression is reduced to approximately the size of the SMC daughters, suggesting that the halo has disappeared (Fig. 2F and G). The possibility that the halo could be an artifact due to oversized SMC cells was ruled out by staining the outlines of cells. Confocal images of different SMCs, like those in Figure 3, showed that although SMCs may be slightly larger than neighboring cells, the size difference cannot account for the inhibition zones. We do not know whether these zones accompany all SMCs in some period of their development. Halos may be masked in clusters sequentially giving rise to many SMCs, like those of the tegula, ventral radius, and wing margin, and difficult to detect in clusters where $s c$ expression is extinguished soon after the appearance of the SMC (ADC and ASC). The existence of halos around the puparium stage-appearing ASA, PPA, and PS precursors has not been examined.

\section{Temporal requirement of ac-sc function for individual $S M C$ determination}

We have shown that SMCs arise among cells of pre-existing proneural clusters. To analyze the temporal requirement of $a c-s c$ for the development of macrochaeta precursors, we have generated homozygous $a c^{+} s c^{+}$and $a c^{-} s c^{-}$cells in $a c^{+} s c^{+} / a c^{-} s c^{-}$heterozygous larvae by mitotic recombination. The ability of these cells to become SOs was compared with that of homozygous $a c^{+} s c^{+}$cells in wild-type larvae. This analysis has been performed for each macrochaetae, in contrast to an earlier study where all macrochaeta were considered together (García-Bellido and Santamaría 1978). Representative examples are shown in Figure 4. Homozygous $a c^{-} S c^{-}$cells resulting from irradiation early in the third larval instar do not develop as macrochaetae. Homozygosity induced later allows some $a c^{-} s c^{-}$cells to become SOs, and after a developmental time characteristic for each $\mathrm{SO}, a c^{-} S c^{-}$chaetae appear as frequently as in the respective control of each $S O$. From this time on, the $a c-s c$ functions are no longer required in the descendants of the irradiated cell to form an SO. For most mac-

Figure 1. Development of the patterns of $s c$ expression (purple) and SO precursors (deep green). Site nomenclature and SMC assignment are according to Bryant (1975), Huang et al. (1991), and our own observations. (A) Disc of $\sim 35$ hr BPF. Note the $s c$ expression in clusters of cells and that only the PSC macrochaeta precursor and that for a dorsal radius sensillum (out of focus, arrowhead) have begun expressing lacZ. (B) Disc of $\sim 25 \mathrm{hr}$ BPF. Several SMCs express lacZ. They correspond to the PDC and APA macrochaetae, the GSR sensillum, one sensillum of the tegula (tg), the anterior notal wing process (anwp), and ventral radius (vr), respectively, and one of the twin sensilla campaniformia of the wing margin $(\mathrm{tsm})$. Note the increased $s c$ expression in a single cell that corresponds to the PSA macrochaeta precursor (arrowhead). (C) Disc of $\sim 20 \mathrm{hr}$ BPF. The PSA precursor has started expressing lacZ. $s c$ expression has started in the presumptive anterior wing margin (wm), in the clusters for the ANP and PNP and other sites where SMCs will appear. (D) Disc of $\sim 10 \mathrm{hr}$ BPF. The wing margin SMCs are detectable by X-gal staining. Note that at the wing margin, both $s c$ and lac $Z$ expressions are first visible in a cluster of cells and a single SMC, respectively, that mark the right (distal) end of the top row ( $B$ and $C$ ). SMC development then progresses leftward up to the proximal end. These precursors most likely correspond to the recurved, multiply innervated bristles of the wing margin since both the precursors and these bristles, but not the straight bristles of the margin, are absent in $I n(1) s c^{10.1}$ flies (not shown). Moreover, the recurved bristles start their final differentiation $\sim 10$ hr earlier than the other margin bristles (Hartenstein and Posakony 1989). At $\sim 10 \mathrm{hr}$ BPF, the precursors for the PNP, ANP (arrowhead), and ASC macrochaetae and the trl sensillum trichoideum below the APA precursor have become visible. Also, within the presumptive notum, the ASA and PPA clusters are already developing. In $E, \sim 5 \mathrm{hr} B \mathrm{PF}$, they have become larger, with more intense $s c$ expression. The corresponding SMCs start expressing lacZ several hours APF (not shown). The ADC macrochaeta precursor has become visible (arrowhead). (F) Disc just before puparium formation. The PS precursor becomes detectable slightly later within an area of intense $s c$ expression (ps). $s c$ (and ac) expression has disappeared from many clusters. Those remaining will give rise to additional SMCs. Note that throughout the 35 hr of development examined, $a c-s c$ are expressed in the prospective anterior and mid-notum, a region that develops $\sim 125$ regularly spaced microchaetae. Their SMCs appear at $\sim 10 \mathrm{hr}$ APF (not shown). All discs are reproduced at the same scale. 


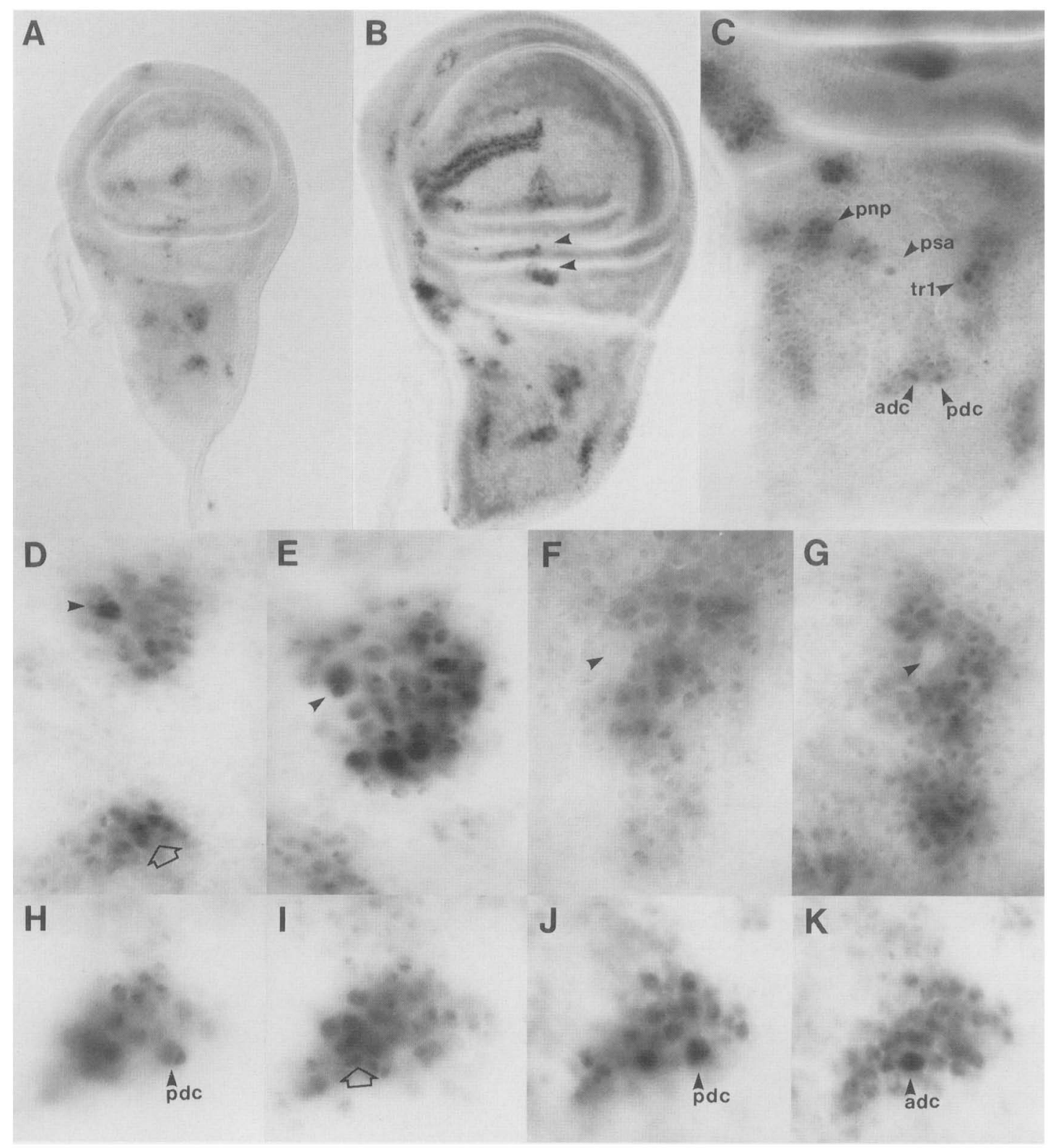

Figure 2. Distribution of $s c$ protein in wing discs of different ages and details of the evolution of the APA and DC clusters. $(A$ and $B$ ) Discs of $\sim 25 \mathrm{hr}$ and $10 \mathrm{hr} B P F$, respectively. The patterns are very similar to those of the $s c \mathrm{mRNA}$ in discs of similar age (Fig. 1B and $D$, respectively). $(C)$ Presumptive notum region of a disc $5 \mathrm{hr} B P F$ at approximately twice the magnification of the discs in $A$ and $B$. Intensely stained nuclei in $A-C$, within or outside clusters, belong to SMCs (cf. their distribution with the $\beta$-galactosidase-expressing cells in discs of Fig. 1). Note in $C$ the eccentric position of the PNP, ADC, PDC, and trl precursors within their clusters and the halo of inhibition associated with the PSA, PNP, and in $B$, with radius sensilla precursors (arrowhead). In the case of the PSA and radius precursors, the halo of inhibition is seen as a decrease in the "background" of staining, suggesting that such background may correspond, at least in part, to a low generalized expression of $a c-s c$. $(D-G)$ Four stages in the evolution of the APA/PPA clusters corresponding to discs of $\sim 25,20,5$, and $0 \mathrm{hr}$ BPF, respectively. ( $D$ also shows in the bottom of the image the DC cluster.) The APA precursor is indicated by an arrowhead. Note its intense staining in $D$ and its enlarged nuclei in $E$. In $F$, the SMC has already divided and stopped expressing $s c$, causing an indentation of the cluster at the site where it is located. In $G$, the cluster has grown in its upper left part, where the tr2 precursor will appear, and the APA precursor position appears as a "hole". In $E$, several intensely stained nuclei are visible at the bottom of the cluster; in this site the trl precursor later appears $(C) .(D, H-K)$ Three stages in the evolution of the DC cluster, approximately corresponding to $25(D), 20(H$ and $I)$, and $10(J$ and $K)$ hr BPF. In $D$ (bottom cluster), several nuclei are intensely labeled (arrow), but the PDC precursor is not yet apparent. Several hours later it is visible in an eccentric position and with a halo of less stained nuclei around it $(H)$. In the same cluster, but in a focal plane separated $4 \mu \mathrm{m}$ from the previous one $(I)$, a group of nuclei contain high amounts of $s c$ protein (arrow). At approximately this site, the ADC precursor will later appear $(K)$. Its focal plane is $3.2 \mu \mathrm{m}$ removed from that of the PDC precursor $(J)$. The widths of $D-K$, obtained with laser transmission microscopy, correspond to $35 \mu \mathrm{m}$. 
rochaetae (Fig. 4, bottom), this occurs when ac-sc are already expressed in the presumptive region (Fig. 1) but 10-25 hr before the time when SMCs become visible by the enhanced expression of $a c-s c$. Exceptionally, for the APA precursor, the time of $a c-s c$ function dispensability occurs approximately when the precursor becomes detectable.

Figure 4 also shows that before the time ac-sc functions appear to become dispensable, the frequency with which homozygous $\mathrm{ac}^{+} \mathrm{sc}^{+}$cells become SMCs in a $a c^{+} s c^{+} / a c^{-} s c^{-}$heterozygous background is two to four times higher than in a homozygous $a c^{+} s c^{+}$background. This indicates that among $a c-s c$-expressing cells, those

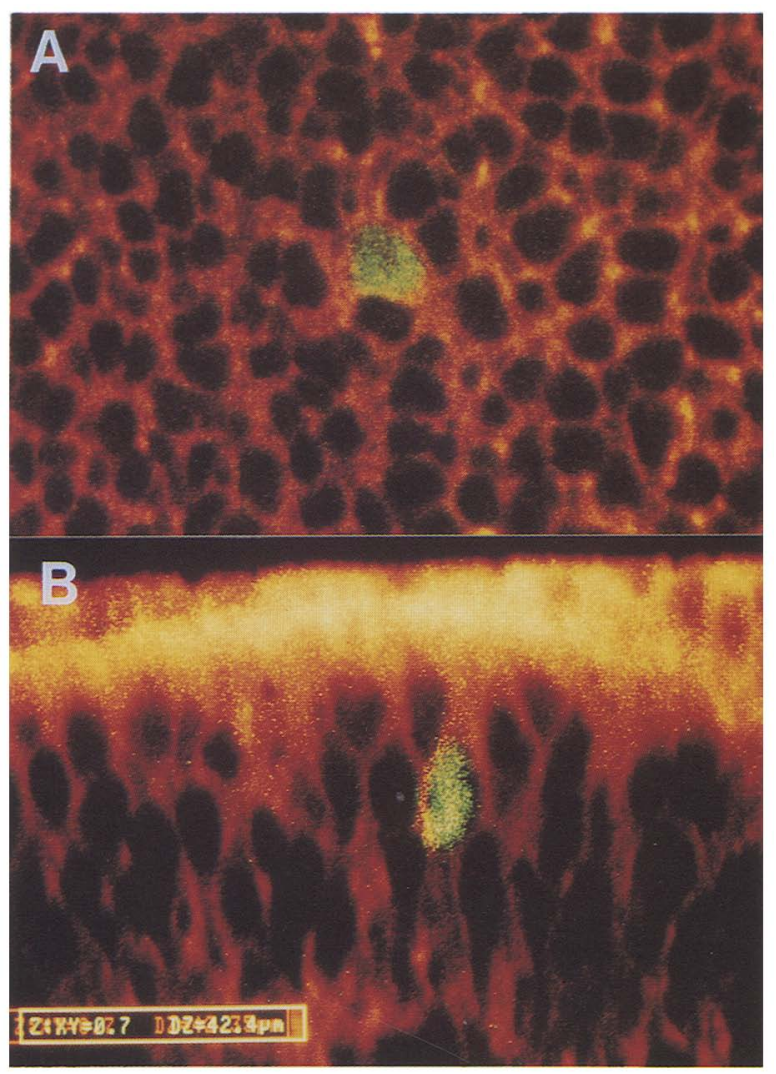

Figure 3. Confocal images of the PDC region of an Al01.1F3 disc of $\sim 10 \mathrm{hr}$ BPF. The PDC precursor nucleus is stained with anti- $\beta$-galactosidase and a fluorescein-conjugated secondary antibody. Cellular periplasms are visualized with a phalloidinrhodamine conjugate, which binds to actin. (A) Optical section parallel to the plane of the notal epithelium at the level of the precursor nucleus. Although slightly larger than neighboring cells, the size difference cannot account for the halos of $a c-s c$ expression inhibition. Similar images were obtained for other SMCs. (B) Optical section perpendicular to the plane of the epithelium. It corresponds to a plane that cuts the image above by an approximately horizontal line that passes through the precursor nucleus. Note that cell nuclei, located in the dark spaces within cells, are organized in different levels of the epithelium and that the nucleus of the precursor is located at an intermediate level. This image has been compressed to $70 \%$ in the $z$-axis. The width of the image in either panel is $45 \mu \mathrm{m}$.
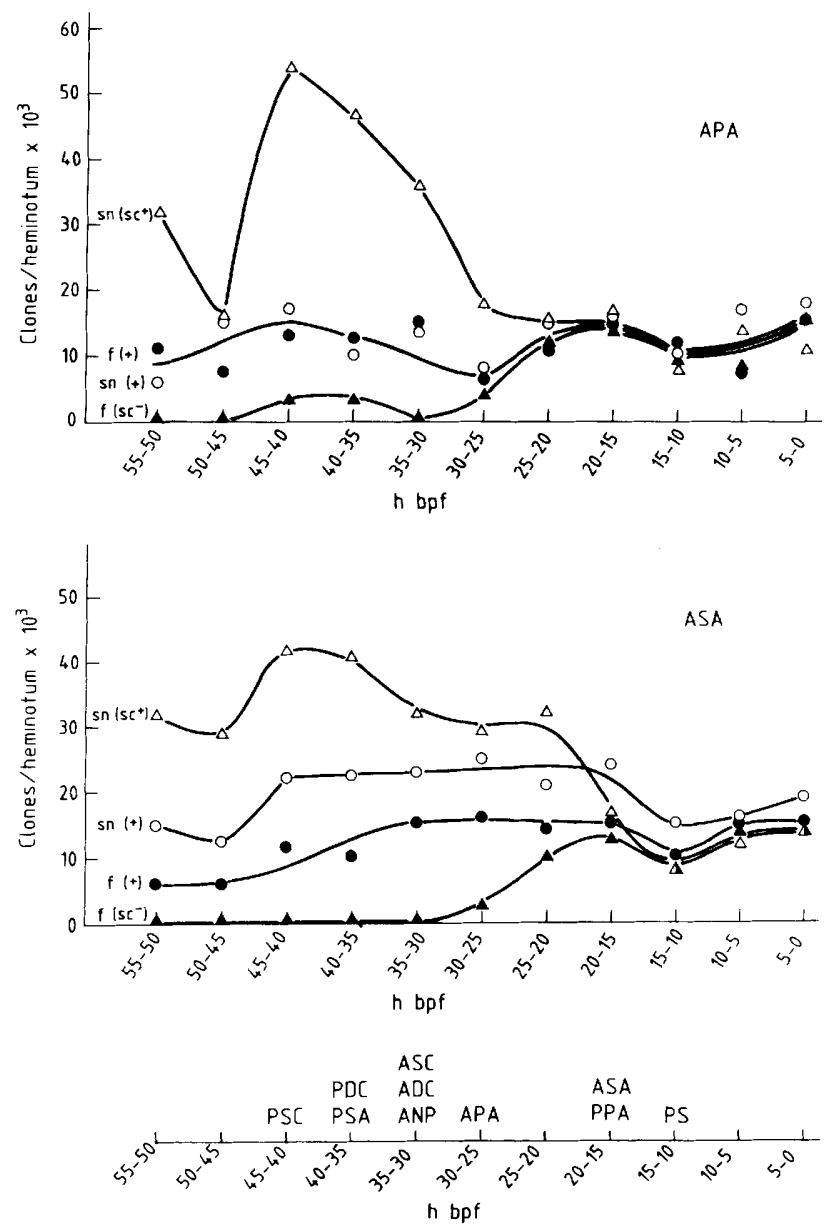

Figure 4. Frequencies of clones, scored as APA- and ASAmarked macrochaetae, obtained by irradiating larvae at different times BFP. The genotypes of the irradiated larvae were $D f(1) s c^{19}, y^{-}, a c^{-}, s c^{-}, f^{36 a} / s n^{3}(\triangle \mathbf{\Delta})$ and $y s^{3} / f^{36 a}$ (○). The genotypes of the scored macrochaeta were $(\triangle) a c^{+} s c^{+} s n^{3} / a c^{+}$ $\left.\left.s c^{+} s n^{3}\left[\mathrm{sn} \mid \mathrm{sc}^{+}\right)\right] ;(\mathbf{\Delta}) a c^{-} s c^{-} f^{36 a} / a c^{-} s c^{-} f^{36 a}\left[\mathrm{f}\left(s c^{-}\right)\right] ;(\mathrm{O}) s n^{3}\right)$ $s n^{3}[\mathrm{sn}|+|] ;\left(\mathbf{O} \mid f^{36 a} / f^{36 a}[\mathrm{f}|+|)\right.$. For early irradiations, the frequency of $s n\left(s c^{+}\right)$macrochaetae is two to four times higher than that of the control $s n(+)$, until a characteristic irradiation time when both values become very similar. At approximately this time, the frequencies of $f\left(s c^{-}\right)$and $f(+)$ also become equal. The lower frequency of $s n\left(s c^{+}\right)$than that of $s n(+)$ in the 20- to $15-$, to $5-$ to 0 -hr period is probably caused by the cis association of $y$ to $s n$ in the control, which facilitates detection of the clones. (Bottom) The time when the frequencies for $f\left(s c^{-}\right)$become similar to those of the respective $(+\mid$ control have been indicated for each macrochaeta, except for the PNP, for which the frequency of clones was extremely low throughout the irradiation period. Comparison with ac-sc-stained discs of different ages indicated that these times occur 10-25 hr before SMCs are visible by their enhanced $a c-s c$ contents. Although irradiation may have exaggerated this interval by delaying development, the estimates for this delay are substantially shorter than this time interval (García-Bellido and Merriam 1971). As with the APA and ASA, irradiation before the indicated times yielded $s n\left(s c^{+}\right)$chaetae with frequencies two to four times higher than those of the control and $f\left(s c^{-}\right)$with frequencies lower or null compared to those of the control. 
with more doses of the $a c^{+} \mathrm{Sc}^{+}$genes, and presumably with the highest level of $a c-s c$ products, have an increased probability to be singled out for becoming SMCs.

\section{sc expression in sc mutants}

To evaluate the significance of the expression pattern of $s c$ for SMC determination, we have examined its modifications in $s c$ mutant discs and compared them with the mutant phenotypes.

$\mathrm{sc}^{6}$ This mutation is a 16-kb deletion located $25 \mathrm{~kb} 3^{\prime}$ from the $s c$-transcribed region. As a result, $s c^{6}$ flies lack the ANP macrochaeta, the tr 2 sensilla trichoidea, and at least two of the three sensilla campaniformia on the ANWP. In agreement with this phenotype, the ANWP and ANP clusters are absent and the APA cluster is reduced. In addition, the level of $s c$ protein in the tegula and PNP clusters is also reduced (Fig. 5A).

$\operatorname{In}(1) \mathrm{sc}^{7}$ This mutation is associated with a breakpoint $\sim 37 \mathrm{~kb} 3^{\prime}$ of the $s c$ structural gene. $s c^{7}$ flies lack the SC macrochaetae, the $\operatorname{tr} 2$ sensilla trichoidea, at least two of the three sensilla campaniformia on the ANWP, part of the recurved bristles of the anterior wing margin, and quite infrequently the PPA macrochaeta (García-Bellido 1979; P. Cubas et al., unpubl.). In accordance with this phenotype, $s c^{7}$ discs lack the SC cluster, and the level of $s c$ protein in the prospective wing margin and APA/PPA and ANWP clusters is reduced (Fig. 5B).

$\operatorname{In}(1) \mathrm{sc}^{4}$ This mutation is associated with a breakpoint $7 \mathrm{~kb} \mathrm{3}$ ' of the $s c$-transcribed region. The levels of $s c$ protein are much lower than in the wild type (see also Romani et al. 1989), although accumulation in clusters is still discernible (not shown). The dorsocentral cluster, whose expression is originally driven by ac (Martínez and Modolell 1991; Skeath and Carroll, this issue), is well developed (Fig. 5C), and the corresponding macrochaetae arise normally. The only other notum macrochaetae usually present are the PNP, APA, and PSA. The corresponding precursors are visible, although their associated clusters are almost undetectable (Fig. 5C). This indicates that a cluster of strongly expressing cells is not essential for development of some macrochaetae.

In $(1) s^{10.1}$ This is a double mutant that maintains intact the $s c$ regulatory regions but lacks functional $s c$ and $a c$ genes and, as a consequence, SOs /García-Bellido and Santamaría 1978). The nonsense mutation in the $s c$ gene (Villares and Cabrera 1987) prevented the use of the anti-sc antibody. Hybridization with an $s c$ probe revealed that $s c^{10.1}$ discs express the $s c$ gene in a pattern that resembles that of the wild-type discs, but with some differences (Fig. 5D). sc mRNA is absent from the sites where expression is originally driven by $a c$, like the dorsocentral and PSA areas (Martínez and Modolell 1991; Skeath and Carroll, this issue). The structure of complex clusters is simplified, because the areas of nonexpression

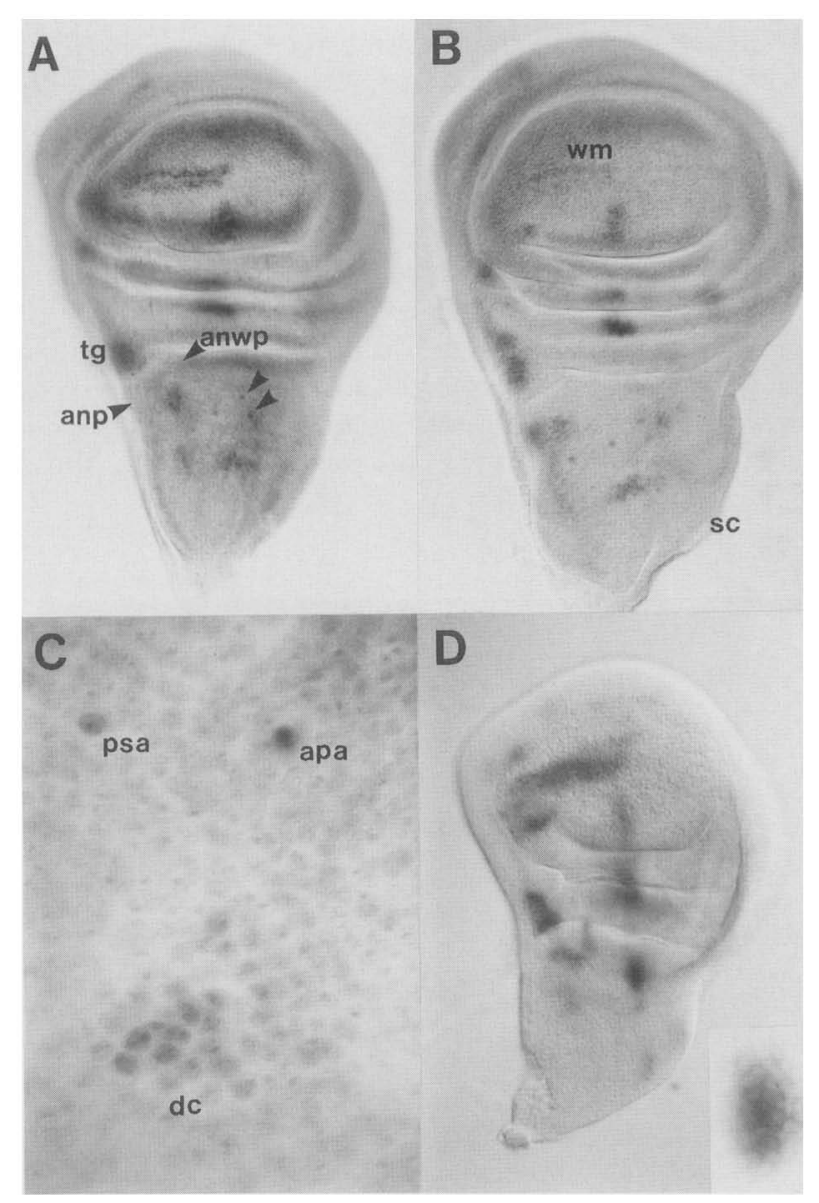

Figure 5. $s c$ expression in discs of $s c$ mutant larvae. (A) $s c$ protein distribution in a $s c^{6}$ mutant disc. Note the absence of the clusters corresponding to the ANP and ANWP regions and the reduction in abundance in the APA and tegula $(\mathrm{tg})$ regions (cf. with the wild-type disc of Fig. 2B). The APA and trl precursors (arrowheads) are simultaneously visible by their increased $s c$ protein content, something not observed in wild-type discs. This suggests that development of the APA precursor is delayed. An SMC that appears very early in the presumptive ANWP region (Fig. 1B) is still present in $s c^{6}$ discs (out of focus), but a later developing one (Fig. 1F) is absent. The first one probably corresponds to the remaining ANWP sensillum campaniforme in the $s c^{6}$ flies. $(B) s c$ protein distribution in a $s c^{7}$ mutant disc. Note the absence of the SC and ANWP clusters and the reduction of expression in the presumptive anterior wing margin (wm) and the APA/PPA region. As in the $s c^{6}$ disc, the APA and trl precursors are simultaneously visible. $(C)$ Central region of the presumptive notum of a $s c^{4}$ disc. The PSA and APA precursors are visible, but the APA cluster is absent. The DC cluster is well developed. Width of the image is $45 \mu \mathrm{m}$. (D) $s c$ mRNA distribution in a $s c^{10.1}$ disc. All sites of expression driven by the $s c$ cis-controlling sequences are present, but those promoted by $a c$, like the PSA and DC areas (cf. with $A$ or Fig. IC and D), are missing. (Inset) The APA cluster at twice the magnification of the disc. Note that it lacks the indentation caused by the APA precursor in wild-type discs of similar age (Fig. 2B). We have confirmed that in $s c^{10.1}$ discs, mRNA abundance, in the sites where it is present, is higher than in the wild type (Romani et al. 1989). The significance of this observation is unknown. Images in $C$ and $D$ were acquired with laser scan transmission microscopy. 
caused by SMCs and associated halos are absent. Thus, the APA cluster has an elliptical shape (Fig. 5D, inset), which lacks the prominent indentation where the APA precursor and its inhibition halo are normally located (Fig. 2F).

\section{Regulation of ac-sc expression by emc}

The emc locus genetically behaves as a trans-regulator of ac-sc (Moscoso del Prado and García-Bellido 1984; García-Alonso and García-Bellido 1988). However, in weak emc mutants, modifications of $a c-s c$ expression were not detected (Romani et al. 1989). We have now compared the $s c$ protein accumulation in discs of the strongest available viable combination of emc alleles $\left(e m c^{p e l} /\right.$ $e m c^{E 12}$ ) with that of wild-type discs, with both types of discs simultaneously stained in the same reaction mixture (Fig. 6A and B). emc $c^{p e l} / e m c^{E 12}$ discs display an increased generalized level of $s c$ protein (Fig. 6B) and a pattern of clusters similar to that of the wild type, although some of the clusters seem enlarged, especially in a broad area covering the ANP, PNP, and DC regions of the presumptive notum. In this area, there is a scatter of strongly labeled nuclei, most easily discernible in discs stained to a lesser extent (Fig. 6C; see also Skeath and Carroll, this issue). These nuclei should correspond to precursors of the ectopic emc bristles, because they are located at the expected positions (García-Alonso and García-Bellido 1988). They seem surrounded by weak, although detectable, halos of inhibition. The increased background of $s c$ protein suggests that $s c$ is derrepressed in this mutant combination.

Achaetous (Ach), a dominant, excess-function allele of emc /García-Alonso and García-Bellido 1988; Garrell and Modolell 1990; H. Ellis and J. Posakony, unpubl.), causes the absence of several notum macrochaetae (ANP, PNP, PPA, and ASA|. Ach discs stain more weakly than wildtype discs with the anti-sc antibody; and SMCs, even those corresponding to present macrochaetae, do not clearly stand out from the remaining cells of the clusters (Fig. 6D). This suggests that $s c$ expression is decreased in Ach discs.

\section{Discussion}

\section{Relation between ac-sc expression clusters and SMCs}

We have shown that during $>35 \mathrm{hr}$ preceding pupariation, $s c$ and $a c$ are expressed in groups of cells of the imaginal wing disc. The patterns of expression evolve with disc growth; clusters appear and disappear at characteristic times. The position, shape, and size of each cluster are very reproducible. Figure 7 schematically summarizes the evolution of a proneural cluster. After a cluster appears in a region of the disc, its number of cells and intensity of expression increase. Some cells, located in reproducible positions within the cluster /and, in some cases, characteristically off-center|, accumulate larger amounts of $a c-s c$ protein, which may indicate that they are nearing the SMC state and are undergoing the

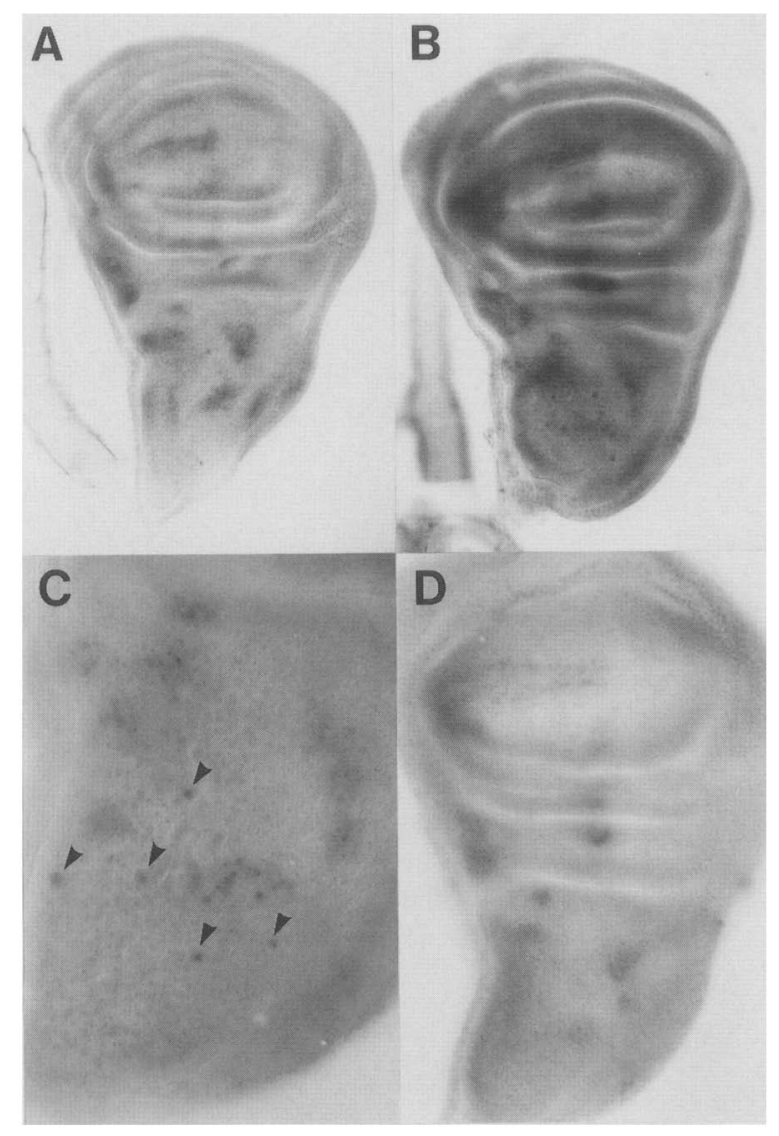

Figure 6. Distribution of $s c$ protein in emc mutants. $(A$ and $B)$ A wild-type and an $e m c^{p e l} / e m c^{E 12}$ disc, respectively. Discs of both phenotypes and of similar ages were treated under exactly the same conditions by carrying the $s c$-staining procedure simultaneously and in the same reaction mixtures. Images were acquired with a transmission laser scanning microscope, and pictures were obtained from the TV screen using the same magnification, brightness, and contrast settings and identical photographic exposures, film development, and printing conditions. The mutant disc has a general level of $s c$ protein higher than the wild-type disc. (C) The presumptive notum region of a similar mutant disc at higher magnification. Single cells in the anterior and medial area of the presumptive notum (arrowheads) contain larger amounts of $s c$ protein than the surrounding cells. This and their location suggests that they correspond to the precursors of the emc extra macrochaetae. (D) A homozygous $A c h$ disc stained with the same antibody. Its clusters have reduced levels of staining when compared to wild-type discs ( $A$ or Fig. 2B), suggesting decreased expression of $s c$. In addition, existing SMCs are barely distinguishable because of the much weaker accumulation of $s c$ protein in their nuclei than in wildtype SMCs. $C$ and $D$ are conventional photomicrographs.

singling-out process. Later, one of these cells, also located in a very reproducible position, acquires the largest amount. This cell is the SMC, because some time later it starts expressing $\beta$-galactosidase in the A101.1F3 strain (Fig. 1), undergoes two differential divisions, and becomes a morphologically recognizable SO (Huang et al. 1991). $a c-s c$ expression in SMCs, which continues until the first differential division, becomes independent of 


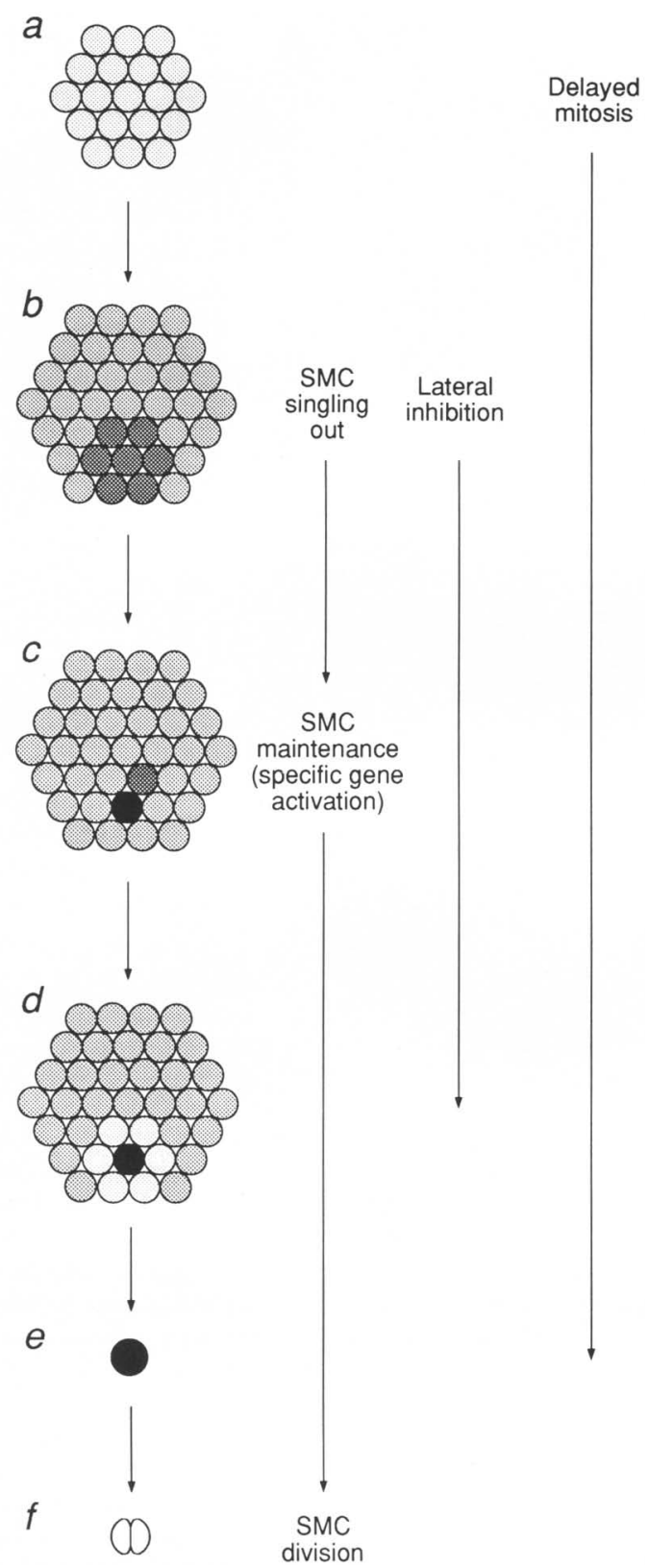

Figure 7. Schematic summary of the development of a proneural cluster and the emergence of an SMC: initially $(a)$, a group of cells start expressing $a c-s c$ (light shading); subsequently $(b)$, the cluster grows in the number of cells and in the intensity of expression. It is unknown whether cluster growth occurs by cell recruitment or by division of cells expressing $a c-s c$. Some cells, in a reproducible position within the cluster and sometimes off the center, contain higher amounts of $a c-s c$ proteins /darker shading). A cell within this territory is selected to become an SMC and starts expressing $a c-s c$ at the highest levels ( in $c)$. Later, in at least some clusters, $a c-s c$ expression is reduced or absent in the SMC neighbors $(d)$. The cluster eventually ceases expressing $a c-s c$, although expression continues in the SMC for some time $(e)$, until it divides $(f)$. (Right) Some developmental operations involved in SMC generation and their tentative temporal relation with the evolution of the proneural cluster are indicated. emc would be involved in $s c$ down-regulation and in antagonizing the proneural effects of the $s c$ product all along the development of clusters and SMCs. expression in the cluster, probably as a result of a specific system of $a c-s c$ activation in these cells (Martínez and Modolell 1991). Thus, SMCs arise within pre-existing $a c$-sc-expressing clusters, in a stereotyped sequence that is intimately related to the evolution of the clusters.

\section{Proneural clusters and the expression of ac-sc}

It has been proposed that each proneural cluster, as defined by the expression of $a c-s c$, is an "equivalence group," which, according to the number of chaetae arising in clones mutant for genes involved in cell-to-cell communication, like Delta $(D I)$ and $\operatorname{Notch}(N)$, would be composed of six or seven cells (Simpson 1990a). However, we find that a mature, average cluster that gives rise to a single macrochaeta contains from 20 to $30 \mathrm{ac}-$ $s c$-expressing cells. This discrepancy suggests that not all cells within a cluster of $a c-s c$ expression are strictly equivalent. The very high reproducibility of the position of an SMC within a cluster suggests that not all of its cells have the same probability to become an SMC in wild-type conditions. This may be due to the different amounts of $a c-s c$ products in the cells, neuralization being possible only above a certain threshold. In support of this interpretation, extra macrochaetae near the extant ones arise when $s c$ is overexpressed in late larval stages (Rodríguez et al. 1990), suggesting that under these conditions more than one SMC is generated from a cluster. Within clusters, additional heterogeneities, independent from the distribution of $a c-s c$ products, modulate the ability of cells to respond to the neuralizing effect of ac-sc (Rodríguez et al. 1990). Evidently, another explanation for the discrepancy could be that the absence of $N$ or Dl does not totally abolish lateral inhibition, or the number of chaetae underestimates the number of SMCs due to the transformation of the external components of the SO into neural cells (Dietrich and Campos-Ortega 1984; Hartenstein and Posakony 1990).

\section{Effects of sc mutations in the pattern of sc expression and in $S O$ generation}

By examining the $s c$ expression in $s c$ mutants and comparing it with the mutant phenotypes, we have found that, in general, there is a good correlation between the absence of an SO and a strong reduction of $s c$ expression in the corresponding cluster. Moreover, SMCs do not develop in the affected positions, as indicated by absence of the corresponding $\beta$-galactosidase-expressing cells in A101.1F3sc; mutant discs (not shown). The results also reveal that positions vary in their quantitative requirements of $s c$ product for developing SOs. Thus, strong reductions in the SC, ANP, ANWP, ASA, and PPA clusters, but not in the APA and PNP clusters, prevent development of the corresponding SOs. In all cases, the development of notum macrochaetae is associated with increased expression of $a c-s c$ in the corresponding SMCs, suggesting that these products are important for starting the developmental program that the precursors will subsequently undergo (Fig. 7). 
It has been proposed that cis-acting elements harbored within the regions $5 \mathrm{~kb}$ upstream and $50 \mathrm{~kb}$ downstream of the $s c$-transcribed region respond to local cues and activate the gene in specific sites of the wing disc (RuizGómez and Modolell 1987; Leyns et al. 1989). The patterns of cluster suppression in $s c^{6}$ and $I n(1) s c^{7}$ support this model. Moreover, because the removal of most of the downstream regulatory region in $I n(1) s c^{4}$ discs still allows weak expression in many clusters, at least part of the elements regulating the basic pattern of $s c$ expression should be located in the neighborhood of the transcribed region. The far removed cis-acting sequences would function as site-specific enhancers.

In the $a c$ and $s c$ null mutant $\operatorname{In}(1) s c^{10.1}$ (Campuzano et al. 1985; Villares and Cabrera 1987), the gross distribution of $s c$ mRNA is similar to that of the wild type, except for the absence of the mRNA in the clusters where expression is driven by ac (Martínez and Modolell 1991). The appearance of the ASA and PPA clusters and the extinction of the ANP cluster also seem to occur at the normal developmental time (not shown). Thus, we suggest that the overall temporal and spatial regulation of $s c$ expression in clusters is independent of the presence of the $a c-s c$ proteins. On the other hand, in the wild type, the fine structure of clusters is affected by the presence of these proteins due to the generation of SMCs and their inhibitory halos (see below). The cross-stimulation between $a c$ and $s c$ and the postulated self-activation of these genes may help to refine the structure of clusters (García-Alonso and García-Bellido 1986; Martínez and Modolell 1991; Skeath and Carroll, this issue).

\section{SMC generation has an early requirement for ac-sc function}

Genetic mosaics of $a c^{-} s c^{-}$cells in $a c^{+} s c^{+} / a c^{-} s c^{-}$larvae had shown that $a c-s c$ functions begin to be dispensable for macrochaetae differentiation as early as $48 \mathrm{hr}$ BPF (García-Bellido and Santamaría 1978). We have now found that for each particular notum macrochaeta, there is a characteristic time after which irradiation yields $a c^{+}{S c^{+}}^{+}$and $a c^{-} s c^{-}$chaetae with frequencies equal to those of the controls (marked $a c^{+} s c^{+}$chaetae in wildtype larvae; Fig. 4). Mitotic recombination induces a change of genotype in the daughters of the irradiated cell. Assuming that the half-life of the $a c-s c$ products is short compared with the $8.5-\mathrm{hr}$ average mitotic cycle in the wing disc (García-Bellido and Merriam 1971), which seems reasonable given the rapid degradation of $s c$ mRNA (Rodríguez et al. 1990) and the relatively fast changes in the expression patterns of $a c-s c$ mRNA and proteins (Figs. 1 and 2), the daughters of the recombinant cell should behave according to their new genotype. ac$s c$ are expressed in SMCs but not in their descendants, suggesting that their functions are required in the former but not in the latter. Therefore, when irradiation yields frequencies of appearance of $a c^{-} s c^{-}$and $a c^{+} s c^{+}$macrochaetae equal to those of the controls, recombination has most likely taken place in the SMC or in the cell that will later become an SMC. Note, however, that the time of dispensability for each macrochaeta starts $10-25 \mathrm{hr}$ before the corresponding SMC is visible by an increased accumulation of ac-sc protein. This may indicate that the singling-out of a macrochaeta precursor occurs from 10 to $25 \mathrm{hr}$ before this accumulation begins. Alternatively, these results may be explained if mitosis is stopped or delayed in a group of cells at the sites where SMCs will emerge (Hartenstein and Posakony 1989; see also Huang et al. 1991) and the decision to single out one of them is taken later (Fig. 7). Because ac-sc expression in clusters is already present at the time of dispensability, perhaps the $a c-s c$ products contribute to delay mitosis. A late singling-out may be supported by the increased levels of ac-sc proteins in several cells at the sites where SMCs later appear and by the inference of a possible reversible "pre-SMC" state visualized by weak lacZ expression in two or more cells at the places where the strongly staining SMC will subsequently emerge (Huang et al. 1991). It is of interest that MyoD, a mammalian protein that shares with $a c-s c$ proteins the bHLH domain and promotes myogenesis, can inhibit cell proliferation independently of myogenic differentiation (Sorrentino et al. 1990). Perhaps the disappearance of ac$s c$ protein from the SMC is a prerequisite for its division.

Irradiation before the time of dispensability yields $a c^{-} s c^{-}$bristles with lower or null frequencies and $a c^{+} s c^{+}$chaetae with frequencies two to four times higher than the controls. Thus, cells with two doses of $a c^{+} s c^{+}$in a background of cells with one dose of $a c^{+} s c^{+}$ have a high probability to become an SMC, suggesting that the levels of $a c-s c$ products are critical for SMC selection. Within a group of cells, the one with the highest levels of $a c-s c$ proteins is favored to become an SMC. This fact could be related to the preferential acquisition of SMC fate of cells with fewer doses of the $N$ gene than their neighbors (de Celis et al. 1991a; Heitzler and Simpson 1991) and to the postulated down-regulation of $a c-$ sc functions by $N$ and $D I$ (Brand and Campos-Ortega 1989; de Celis et al. 1991b).

\section{as-sc expression is reduced in cells adjacent to SMCs}

We have seen for several positions that after SMCs have preferentially accumulated $a c-s c$ proteins, the surrounding cells, up to a distance of one or two cell diameters, do not express $a c-s c$ or express it at lower levels than those of the other cells of the cluster (Fig. 7). Although we do not know whether this phenomenon occurs for most or all SMCs, it may be related to lateral inhibition, a mechanism postulated to prevent most cells of the cluster from becoming SMCs (Wigglesworth 1940; for review, see Simpson 1990b|. Still, because mosaic analysis of cells with different doses of $a c-s c$ or $N$ (see above) indicates that lateral inhibition already operates in the process of SMC singling-out, that is, before the appearance of the precursor, the late occurrence of the "halo" and the increased levels of $a c-s c$ proteins in the precursor may reflect the maintenance by cell interactions of the non-SMC and SMC cellular states reached earlier. In the case of the APA precursor, after this cell has ceased ex- 
pressing $a c-s c$, the surrounding halo disappears (Fig. $2 F, G)$, suggesting that the halo is a consequence of the increased $a c-s c$ expression in the SMC. Candidates to mediate this inhibition are the "neurogenic" genes (Artavanis-Tsakonas 1988; Campos-Ortega 1988). neuralized is specifically expressed in SMCs /G. Boulianne, A. de la Concha, J.A. Campos-Ortega, L.Y. Jan, and Y.N. Jan, pers. comm.). Another candidate recently proposed to be involved in lateral inhibition is scabrous, a gene that encodes a secreted peptide and whose expression, controlled by $a c-s c$, is maximal in SMCs (Mlodzik et al. 1990).

\section{emc regulates sc expression and function}

In discs carrying a strong but viable loss-of-function emc heteroallelic combination, the amount of $s c$ protein is ubiquitously increased and at least some clusters of $s c$ expression are somewhat enlarged. In contrast, discs carrying the emc excess-function Ach allele show the opposite effects. These results provide direct evidence for $e m c$ regulation of $s c$ expression, as inferred previously from genetic analyses (Moscoso del Prado and GarcíaBellido 1984; García-Alonso and García-Bellido 1988), and support the proposal that emc participates in the generation of the pattern of $s c$ expression (Moscoso del Prado and García-Bellido 1984). However, the structure of the emc product, an HLH protein that lacks the basic region important for DNA interaction (Ellis et al. 1990; Garrell and Modolell 1990), makes unlikely a direct regulation of $s c$ transcription by this protein. Rather, it may interfere with $s c$ activation promoted by other HLH proteins ( $a c$, sc, da, etc.) (García-Alonso and García- Bellido 1986; Dambly-Chaudière et al. 1988; Martínez and Modolell 1991; Skeath and Carroll, this issue) by sequestering them in inactive heterodimers. Considering that emc is ubiquitously expressed (Ellis et al. 1990; Garrell and Modolell 1990), its product would simultaneously prevent generalyzed $s c$ activation and help refine the configuration of clusters, by allowing $s c$ expression only above a certain threshold of HLH activators. We should stress that the emc protein probably also interferes with the proneural activity of $a c-s c$ proteins by complexing them and preventing their interaction with target genes involved in SMC development (Ellis et al. 1990; Garrell and Modolell 1990). Thus, we conclude that the emc function in chaetae pattern formation is most likely carried out both by controlling $s c$ transcription and by limiting the amount of $s c$ protein available for proneural action.

\section{Materials and methods}

Drosophila stocks

The genetic and molecular descriptions of the emc alleles used $\left(e m c^{p e l}, e m c^{E 12}, A c h\right)$ are found in García-Alonso and GarcíaBellido (1988) and Garrell and Modolell (1990). To obtain em$c^{p e l} / e m c^{E 12}$ larvae, emc $c^{p e l}$ homozygous females were crossed to $D f(3 L) e m c^{E 12} / \mathrm{TM} 6 \mathrm{~b}, \mathrm{Hu}, \mathrm{Tb}$ males and $\mathrm{Tb}^{+}$larvae were selected.
The A101.1F3 stock is a transformant line obtained by Hugo Bellen and co-workers in W. Gehring's laboratory. It expresses the lacZ gene in SMCs (Huang et al. 1991) and was kindly provided by $\mathrm{H}$. Bellen. Other stocks used are from the collection of A. García-Bellido and are described in Lindsley and Grell (1968). Molecular descriptions of $s c$ mutants can be found in Campuzano et al. (1985) and Villares and Cabrera (1987).

\section{Larval age determination}

To select individuals of specific ages, Drosophila melanogaster (Oregon-R or A101.1F3) flies, which were laying well, were allowed to lay eggs for $2 \mathrm{hr}$ in standard 1-pint food bottles. Adults were removed and, after $72 \mathrm{hr}$ or more of development at $25^{\circ} \mathrm{C}$, part of the larvae were removed from a large piece of the food pellet and wing discs were dissected out. The age of these larvae, in hours BPF, was determined by comparison with the time when their siblings reached the white pupae stage fat $120 \pm 4 \mathrm{hr}$ after egg laying). For late wandering larvae, a group was removed from the culture bottles; part of the group was dissected, and the rest was allowed to pupariate. Groups for age determination contained at least 50 individuals.

\section{In situ hybridization in imaginal disc whole mounts}

Unless otherwise indicated, all solutions were made in PBS. Imaginal discs were dissected and fixed by treatment in $4 \%$ paraformaldehyde for $20 \mathrm{~min}$ at room temperature, washed in PBS, inmersed in $0.5 \%$ glutaraldehyde for 2 min on ice, washed again, and treated for $20 \mathrm{~min}$ at room temperature with $4 \%$ paraformaldehyde, $0.1 \%$ Triton $\mathrm{X}-100$, and $0.1 \%$ deoxycholate. After a 5-min wash and two washes in $0.1 \%$ Tween (PBT), discs were digested with Boehringer proteinase $\mathrm{K}(50 \mu \mathrm{g} / \mathrm{ml}$ in PBT) for $2 \mathrm{~min}$. Following digestion, discs were washed, refixed in $4 \%$ paraformaldehyde, prehybridized, and hybridized at $45^{\circ} \mathrm{C}$, as described by Tautz and Pfeifle (1989), using DIG-labeled $a c$ or $s c$ cDNAs as probes. These probes were prepared according to the manufacturer's instructions (Boehringer Manheim) and used at $\sim 60 \mathrm{ng} / \mathrm{ml}$. After hybridization, discs were washed at $45^{\circ} \mathrm{C}$ and incubated for $1 \mathrm{hr}$ at room temperature in a $\frac{1}{2000}$ dilution of anti-DIG antibody conjugated to alkaline phosphatase. Immediately before using, the antibody was preabsorbed for $1 \mathrm{hr}$ with fixed larval heads. After alkaline phosphatase activity detection, discs were washed in PBT, dehydrated, and mounted in Canada balsam.

To double-label discs by X-gal staining and in situ hybridization, discs were incubated, after the glutaraldehyde fixation and a 5 -min wash in PBS, at $37^{\circ} \mathrm{C}$ for $2 \mathrm{hr}$ in the X-gal staining solution described in Romani et al. (1989), supplemented with $0.3 \%$ Triton X-100. After washing with PBS and PBT, the hybridization protocol was then continued from the proteinase $\mathrm{K}$ digestion step, as described above.

\section{Antibody staining}

Oregon-R imaginal discs were hand-dissected in PBS and fixed as described in Romani et al. (1989). After fixation and washing in $0.3 \%$ Triton X-100 in PBS (PB-Triton), the tissue was blocked for $\mathrm{l} \mathrm{hr}$ at room temperature in $\mathrm{PB}-$ Triton containing $10 \mathrm{mg} / \mathrm{ml}$ of bovine serum albumin (PBTB). Following an overnight incubation at $4^{\circ} \mathrm{C}$ with a monoclonal anti-ac antibody, diluted $1: 20$, or a rabbit anti-sc antibody (Skeath and Carroll, this issue), diluted $1: 1000$ in PBTB, discs were washed three times in PB-Triton, blocked again in PBTB for $1 \mathrm{hr}$, and incubated with the appropriate peroxidase-conjugated secondary antibodies [sheep anti-mouse IgG-HRP (Amersham) or sheep anti-rabbit 
IgG-HRP (Boehringer)] for $2 \mathrm{hr}$ at room temperature. Discs were washed again with three changes of $\mathrm{PB}-\mathrm{Triton}$, and the peroxidase signal was developed in $0.5 \mathrm{mg} / \mathrm{ml}$ of diaminobenzidine in PBS containing $0.03 \% \mathrm{Co}^{2+}$ and $\mathrm{Ni}^{2+}$ and $0.02 \% \mathrm{H}_{2} \mathrm{O}_{2}$. After staining, discs were dehydrated, cleared in xylene, and mounted in Canada balsam. Double staining with phalloidin-rhodamine conjugate (Sigma) and anti- $\beta$-galactosidase antibody was carried out by the simultaneous overnight incubation, at $4^{\circ} \mathrm{C}$ and in the dark, of discs, prepared as described above, with $0.05 \mathrm{mg} / \mathrm{ml}$ of phalloidin-rhodamine and rabbit anti- $\beta$-galactosidase antibody (diluted $1: 2000$ ) in PBTB. After washing, discs were incubated with swine anti-rabbit IgG-FITC conjugate (Dakopatts), washed, and mounted in $N$-propyl-gallate. Where indicated, images where acquired with a Zeiss laser scan microscope (LSM), either in the transmission (HRP staining) or confocal modes (fluorescent staining).

\section{Clonal analysis}

Mitotic recombination was induced by X-rays at a dose of 1000 rads (Philips M6-15/Be tube, $100 \mathrm{kV}, 15 \mathrm{~mA}$, with a $2-\mathrm{mm} \mathrm{Al}$ filter, at $20 \mathrm{~cm}$ focal distance). Larvae resulting from $24 \mathrm{hr}$ of egg laying by 40 females were grown at $25^{\circ} \mathrm{C}$ in 1-pint bottles containing an agar, yeast, flour, and brown sugar medium. These conditions prevented overcrowding. After irradiation, cultures were left to age at $25^{\circ} \mathrm{C}$, all pupae were collected every $5 \mathrm{hr}$, and each group of pupae were left to develop in separate culture tubes. Irradiated larvae were of two genotypes: $D f(1) s c^{19}, y^{-}$, $a c^{-}, s c^{-}, f^{36 a} / s n^{3}$, obtained from a cross of females $D f(1) s c^{19}$, $f^{36 a} /$ FM6 $\times$ males $s n^{3}$, and y $s n^{3} / f^{36 a} ; m w h j v^{70 b} /+$, prepared from a cross of females y $s n^{3} \times$ males $f^{36 a} ; m w h j v^{70 b}$. Marked macrochaetae were scored under a dissecting microscope. Between 500 and 800 heminota were examined for each genotype and each developmental interval.

\section{Acknowledgments}

We are most grateful to S. Carroll, J. Skeath, F. Jiménez, A. García-Bellido, and colleagues in our laboratories for illuminating discussions and constructive suggestions on this paper; to $S$. Carroll and J. Skeath for gifts of the anti- $a c$ and anti-sc antibodies and for sharing their findings with us; and to J. Garrell for help in computer drawing. P.C. and J.F. de C. are predoctoral and postdoctoral fellows of the Comunidad Autónoma of Madrid and Ministerio de Educación y Ciencia, respectively. This work was supported by grant PB87-0433-C02-01 from Dirección General de Investigación Científica y Técnica (DGICYT) and an institutional grant from Fundación Ramón Areces to the Centro de Biología Molecular.

The publication costs of this article were defrayed in part by payment of page charges. This article must therefore be hereby marked "advertisement" in accordance with 18 USC section 1734 solely to indicate this fact.

\section{References}

Artavanis-Tsakonas, S. 1988. The molecular biology of the Notch locus and the fine tuning of differentiation in Drosophila. Trends Genet. 4: 95-100.

Balcells, L., J. Modolell, and M. Ruiz-Gómez. 1988. A unitary basis for different Hairy-wing mutations of Drosophila melanogaster. EMBO I. 7: 3899-3906.

Bate, M. 1978. Development of sensory systems in arthropods. In Handbook of sensory physiology. Springer-Verlag, Berlin.

Botas, J., J. Moscoso del Prado, and A. García-Bellido. 1982.
Gene-dose titration analysis in the search of trans-regulatory genes in Drosophila. EMBO I. 1: 307-310.

Brand, M. and J.A. Campos-Ortega. 1989. Two groups of interrelated genes regulate early neurogenesis in Drosophila melanogaster. Wilhelm Roux's Arch. Dev. Biol. 197: 457-470.

Bryant, P.J. 1975. Pattern formation in the imaginal wing disc of Drosophila melanogaster: Fate map, regeneration and duplication. J. Exp. Zool. 193: 49-78.

Campos-Ortega, J.A. 1988. Cellular interactions during early neurogenesis in Drosophila melanogaster. Trends Neurosci. 11: 400-405.

Campuzano, S., L. Carramolino, C.V. Cabrera, M. Ruiz-Gómez, R. Villares, A. Boronat, and J. Modolell. 1985. Molecular genetics of the achaete-scute gene complex of $\mathrm{D}$. melanogaster. Cell 40: 327-338.

Campuzano, S., L. Balcells, R. Villares, L. Carramolino, L. García-Alonso, and J. Modolell. 1986. Excess function Hairywing mutations caused by gypsy and copia insertions within structural genes of the achaete-scute locus of Drosophila. Cell 44: 303-312.

Caudy, M., H. Vässin, M. Brand, R. Tuma, L.Y. Jan, and Y.N. Jan. 1988. daughterless, a Drosophila gene essential for both neurogenesis and sex determination, has sequence similarities to myc and the achaete-scute complex. Cell 55: 10611067.

Dambly-Chaudière, C., A. Ghysen, L.Y. Jan, and Y.N. Jan. 1988. The determination of sense organs in Drosophila: Interaction of scute with daughterless. Wilhelm Roux's Arch. Dev. Biol. 197: 419-423.

de Celis, J.F., M. Mari-Beffa, and A. García-Bellido. 1991a. Cell autonomous role of the Notch gene, an epidermal growth factor homolog, in sensory organ differentiation in Drosophila. Proc. Natl. Acad. Sci. 88: 632-636.

de Celis, J.F., M. Mari-Beffa, and A. García-Bellido. 1991b. Function of trans-acting genes of the achaete-scute complex in sensory organ patterning in the mesonotum of Drosophila. Wilhelm Roux's Arch. Dev. Biol. (in press).

Dietrich, U. and J.A. Campos-Ortega. 1984. The expression of neurogenic loci in imaginal epidermal cells of Drosophila melanogaster. J. Neurogenet. 1: 315-332.

Ellis, H.M., D.R. Spann, and J.W. Posakony. 1990. extramacrochaetae, a negative regulator of sensory organ development in Drosophila, defines a new class of helix-loop-helix proteins. Cell 61: 27-38.

García-Alonso, L. and A. García-Bellido. 1986. Genetic analysis of Hairy-wing mutations. Wilhelm Roux's Arch. Dev. Biol. 195: 259-264.

1988. extramacrochaetae, a trans-acting gene of the achaete-scute complex of Drosophila involved in cell communication. Wilhelm Roux's Arch. Dev. Biol. 197: 328-338.

García-Bellido, A. 1979. Genetic analysis of the achaete-scute system of Drosophila melanogaster. Genetics 91: 491-520.

García-Bellido, A. and J. Merriam. 1971. Parameters of the wing imaginal disc development of Drosophila melanogaster. Dev. Biol. 24: 61-87.

García-Bellido, A. and P. Santamaría. 1978. Developmental analysis of the achaete-scute system of Drosophila melanogaster. Genetics 88: 469-486.

Garrell, J. and J. Modolell. 1990. The Drosophila extramacrochaetae locus, an antagonist of proneural genes that, like these genes, encodes a helix-loop-helix protein. Cell 61: 3948.

Ghysen, A. and C. Dambly-Chaudière. 1989. Genesis of the Drosophila peripheral nervous system. Trends Genet. 5: 251-255.

Hartenstein, V. and J.W. Posakony. 1989. Development of adult 
sensilla on the wing and notum of Drosophila melanogaster. Development 107: 389-405.

1990. A dual function of the Notch gene in Drosophila sensillum development. Dev. Biol. 142: 13-30.

Heitzler, P. and P. Simpson. 1991. The choice of cell fate in the epidermis of Drosophila. Cell 64: 1083-1092.

Huang, F., C. Dambly-Chaudière, and A. Ghysen. 1991. The emergence of sense organs in the wing disc of Drosophila. Development (in press).

Jan, Y.N. and L.Y. Jan. 1990. Genes required for specifying cell fates in Drosophila embryonic nervous system. Trends Neurosci. 13: 493-498.

Lawrence, P.A. 1966. Development and determination of hairs and bristles in the milkweed bug Oncopeltus fasciatus (Lygaeidae, Hemiptera). J. Cell. Sci. 1: 475.

Leyns, L., C. Dambly-Chaudière, and A. Ghysen. 1989. Two different sets of cis elements regulate scute to establish two different sensory patterns. Wilhelm Roux's Arch. Dev. Biol. 198: $227-232$.

Lindsley, D.L. and E.H. Grell. 1968. Genetic variations of Drosophila melanogaster. Carnegie Inst. Wash. Publ.

Martínez, C. and J. Modolell. 1991. Cross-regulatory interactions between the proneural achaete and scute genes of Drosophila. Science 251: 1485-1487.

Mlodzik, M., N.E. Baker, and G.M. Rubin. 1990. Isolation and expression of scabrous, a gene regulating neurogenesis in Drosophila. Genes \& Dev. 4: 1848-1861.

Moscoso del Prado, J. and A. García-Bellido. 1984. Genetic regulation of the achaete-scute complex of Drosophila melanogaster. Wilhelm Roux's Arch. Dev. Biol. 193: 242-245.

Murre, C., P.S. McCaw, and D. Baltimore. 1989a. A new DNA binding and dimerization motif in immunoglobin enhancer binding, daughterless, MyoD and myc proteins. Cell 56: 777-783.

Murre, C., P.S. McCaw, H. Vaessin, M. Caudy, L.Y. Jan, Y.N. Jan, C.V. Cabrera, J.N. Buskin, S.D. Hauschka, A.B. Lassar, $\mathrm{H}$. Weintraub, and D. Baltimore. 1989b. Interactions between heterologous helix-loop-helix proteins generate complexes that bind specifically to a common DNA sequence. Cell 58: 537-544.

Rodríguez, I., R. Hernandez, J. Modolell, and Mi. Ruiz-Gómez. 1990. Competence to develop sensory organs is temporally and spatially regulated in Drosophila epidermal primordia. EMBO /. 11: 3583-3592.

Romani, S., S. Campuzano, E. Macagno, and J. Modolell. 1989. Expression of achaete and scute genes in Drosophila imaginal discs and their function in sensory organ development. Genes \& Dev. 3: 997-1007.

Ruiz-Gómez, M. and J. Modolell. 1987. Deletion analysis of the achaete-scute locus of D. melanogaster. Genes \& Dev. 1: 1238-1246.

Rushlow, C.A., A. Hogan, S.M. Pinchin, K.M. Howe, M. Lardelli, and D. Ish-Horowicz. 1989. The Drosophila hairy protein acts in both segmentation and bristle patterning and shows homology to N-myc. EMBO I. 8: 3095-3103.

Simpson, P. 1990a. Lateral inhibition and the development of the sensory bristles of the adult peripheral nervous system of Drosophila. Development 109: 509-519.

- 1990b. Notch and the choice of cell fate in Drosophila neuroepithelium. Trends Genet. 6: 343-345.

Sorrentino, V., R. Pepperkok, R.L. Davis, W. Ansorge, and L. Philipson. 1990. Cell proliferation inhibited by MyoD1 independently of myogenic differentiation. Nature 345: 813815.

Tautz, D. and C. Pfeifle. 1989. A non-radioactive in situ hybridization method for the localization of specific RNAs in
Drosophila embryos reveals translational control of the segmentation gene hunchback. Chromosoma 98: 81-85.

Villares, R. and C.V. Cabrera. 1987. The achaete-scute gene complex of $D$. melanogaster: Conserved domains in a subset of genes required for neurogenesis and their homology to myc. Cell 50: 415-424.

Wigglesworth, V.B. 1940. Local and general factors in the development of "pattern" in Rhodnius prolixus (Hemiptera). I. Exp. Zool. 17: 180-220. 


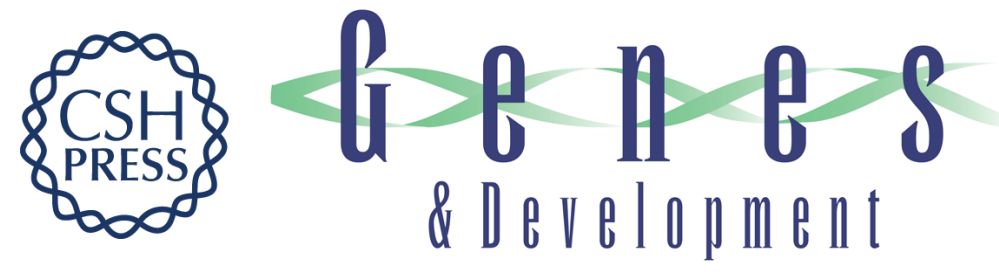

\section{Proneural clusters of achaete-scute expression and the generation of sensory organs in the Drosophila imaginal wing disc.}

P Cubas, J F de Celis, S Campuzano, et al.

Genes Dev. 1991, 5:

Access the most recent version at doi:10.1101/gad.5.6.996

References This article cites 41 articles, 10 of which can be accessed free at:

http://genesdev.cshlp.org/content/5/6/996.full.html\#ref-list-1

License

Email Alerting

Service

Receive free email alerts when new articles cite this article - sign up in the box at the top right corner of the article or click here.

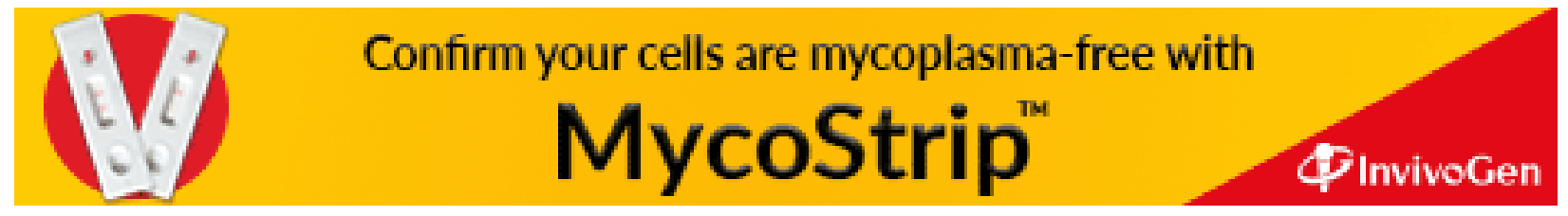

